\title{
Making the implicit explicit: raising pragmatic awareness in trainee interpreters, using semi -authentic spontaneous discourse samples
}

\section{Annette Sachtleben and Heather Denny. AUT University, Auckland, New Zealand}

\section{Research issue}

Recent recognition of the importance of pragmatics in communication has led to an interest in teaching pragmatics in language teaching. Pragmatics are concerned with the culturally determined 'rules' of interaction. They include the sociopragmatic norms - the shared cultural understandings in a community for successful communication, for example the meaning of silence in different contexts. Pragmalinguistic norms or the language that is used to express these values are also included, for example the use of 'possibly' to soften a request in a problematic situation (Yates, 2004). An understanding of pragmatics is important, not only for people who settle in a country where the dominant language and culture is not their own (Eslami-Rasekh, 2005; Kasper \& Roever, 2004) but, by implication, for those who interpret for them. For advanced learners, pragmatic infelicities can be less acceptable to native speakers (Bardovi-Harlig \& Dörnyei, 1998) than grammatical errors. For trainee interpreters, who are advanced learners, knowledge of these norms is vital because their ability to interpret or convey intended pragmatic meaning is essential, and mistakes can lead to serious miscommunication.

Our research issue was therefore how best to teach pragmatics to an undergraduate interpreting class. In English classes for migrants and refugee adults at intermediate level in Auckland New Zealand, the pragmatics of New Zealand English (NZE) had been successfully taught using semi-authentic recorded samples of spontaneous native speaker role-play (Denny, 2008). We wanted to know if similar samples would be of use in raising the pragmatic awareness of trainee interpreters. In this endeavour the class teacher (the first author) worked with a collaborating researcher-practitioner (the second author) in a self-study enquiry.

\section{The participants and class}

This under-graduate class of trainee interpreters consisted of one New-Zealand born and twenty-eight migrant students. These had been in New Zealand for varying lengths of time, ranging from many years to as little as three weeks. There were 27 females and two males.

Languages spoken

\begin{tabular}{|l|l|l|l|l|l|l|l|l|l|l|l|}
\hline Mandarin & Cantonese & Japanese & Korea & Bulgarian & French & Hungarian & NZE/Maori & Punjabi & Russian & Tongan & Urdu \\
14 & 3 & 2 & 2 & 1 & 1 & 1 & 1 & 1 & 1 & 1 \\
1
\end{tabular}

Age range

\begin{tabular}{|l|l|l|}
\hline $20-30$ & $31-40$ & $41+$ \\
\hline 19 & 9 & 1 \\
\hline
\end{tabular}


Class learning focused on the parameters of English oral discourse, and included English phonology and pronunciation and New Zealand English pragmatic norms. Idiomatic language and basic interpreting skills were also addressed.

\section{Background literature}

Research has shown that the explicit teaching of pragmatic norms, especially instruction involving some metacognition, can help language learners (Rose, 2005). In addition, having learners notice features in naturalistic discourse rather than more artificial scripted textbook samples can be more effective (Basturkmen, 2002; Gilmore, 2004; Riddiford, 2007).

Because of difficulties teachers have (lack of time, expertise or resources) in accessing suitable authentic texts for the specific needs of their learners (Denny \& Basturkmen, 2009), recorded spontaneous native speaker role-play has been used (Denny, 2008). These texts, though not fully authentic, represent a distillation of native speaker implicit knowledge of pragmatic norms (Golato, 2003). Typically guided consciousness-raising tasks are used, in which learners are helped to notice, discuss and practise pragmatic features in such samples.

However suitable teaching materials using this approach are not readily available. One way teachers can take part in materials development and explore innovative ways of using them is through collaborative action research projects (Burns, 2000). Action research is a powerful form of development activity in which teachers retain control of their own agenda. The teacher gathers data on an aspect of his/her practice, reflects on the data, draws conclusions, asks new questions and researches these in a cyclical process akin to reflective practice (Burns, 2000; Farrell, 2008). The researching teacher can work with a colleague who acts as critical friend (Louie, Drevdahl, Purdy, \& Stackman, 2003).

\section{Procedures}

\section{Teaching methodology}

The terminology for pragmatic analysis was given in an online glossary at the beginning of the course. Examples were included.

Three recordings were created for the interpreting class using spontaneous native speaker role play in three situations involving face threatening acts: clarification and repair after an inferred insult, a complaint with resolution, and disagreement avoidance. An extract from the second is included here:

\section{A female manager $(\mathrm{H})$ to a junior male colleague $(\mathrm{G})$}

$\mathrm{H}$ : Oh, hi Graeme. How's it going?

G: $\quad$ Oh ...(sigh)... OK well... oh not that w... not that well really, actually.

$\mathrm{H}$ : Why what, what's the [matter?

G: $\quad$ [Oh, a lot of stuff happening at home......... 
In the classroom in six successive weeks half of one sample was played twice without comment. Through teacher elicitation the context, relationship between the speakers and purpose of the utterances became clear, and with repeated listening the use of stress, intonation, repetition of words or other devices used for pragmatic effect was clarified. Next task sheets were distributed with the script. The tasks required the students explicitly to identity the words signaling the stages of the discourse, and the pragmatic effect of certain words, such as (from the above sample) 'OK, well' 'actually'. Answers could be provided individually, through pair work or in small group work, depending on the students' preferences. When an incorrect answer was given, it was not rejected, but was a basis for class discussion. Finally the students identified what problems would arise when interpreting the text to give a similar pragmatic meaning.

In many instances there was not one single correct answer, as pragmatic understanding relies on individual interpretation. However the NZE sociocultural expectations were clarified in the classroom. The samples were then put online for further individual analysis and review as homework. The use of stress and intonation was of particular interest to those students whose first language did not use such markers for pragmatic effect.

Each fortnight, the students were required to write a blog where they transcribed a very brief conversation (or part thereof) that they had participated in or overheard. (See appendix 1). This conversation was then analysed by the student for its pragmatic content, demonstrating classroom learning. As the course progressed and more pragmatic features were introduced in the classroom, the students' analyses became more varied.

\section{Research methodology}

In the literature on language acquisition it is now widely accepted that 'noticing' and conscious awareness is a precondition for acquiring features of a second language (Schmidt, 1990). However when a learner becomes aware of a new feature of the second language he or she is less likely initially to show this awareness in production under demanding test conditions or when engaged in a multi-tasking situation such as simultaneous interpreting (House, 1996). In order, therefore, to measure awareness which is the precursor to production, it is necessary to use a data-gathering tool that allows the learners to show initial awareness without time or test pressure. We decided to use learner blogs as our main data collection tool. Here the learner reflects on what he or she has noticed, relates it to his/her experience and compares it with equivalent features in his/her first language and culture.

These blogs were analysed by the class-room based teacher and the researcher-practitioner. Learner data was triangulated by the use of a teacher journal recording teacher perceptions of the effectiveness of the learning materials and approach and perceived developments in the learners' awareness. The teacher journal was analysed by the teacher herself and the key themes (such as the effectiveness of the learning material and the approach) identified. 
All students wrote the compulsory reflective blogs, but only consenting students' blogs were used as data. Processes for gaining consent were approved by the University's Ethics Committee. In four fortnightly blogs (See Appendix 1) learners wrote about the pragmatic features they noticed in conversations heard or participated in outside of the classroom. We identified and coded for instances in the blogs in which learners noticed and described features used for pragmatic purpose and also where they noticed and commented on cross-cultural pragmatic differences (See appendix 2 for features). For example, the coding (in square brackets) in Blog2:

Uncle J : I've forgot ...... how to use MSN. Ann teach me again after dinner, OK.

[Student comment]...Uncle J needs help but he sounds like giving a command... [speech act] to Ann. 'OK' here is not asking........ 'OK' means waiting for her answer.... he is not expecting to be rejected. [discourse marker]

Coding was moderated to ensure consistency and accuracy. We then treated as baseline data the first blog which was completed in week 2 when teaching of pragmatics began. We compared the number of students who noticed pragmatic features discussed in class in this blog with the number who noticed the same features in subsequent blogs to quantify growth in students' awareness as learning progressed.

\section{Results}

Summarized results of the analysis of leaner blogs are shown in Appendix 2. Pragmatic features dealt with are listed, including those noticed in the sample texts and those which were identified in follow-up class discussions. The results show that for all the pragmatic features listed, the number of students showing awareness increased, indicating that the teaching methodology based on analysis of spontaneous spoken texts, classroom discussion and learner blogging was effective. There was considerable variation between individuals' noticing of pragmatic features. Variables included personality type, length of residence in New Zealand, and the level of contact with native speakers. Assessment results showed that those students who had been in New Zealand for the shortest time and had had the least contact with a range of native speakers were generally the weakest in noticing the targeted features.

The results also show that the most important area of growth in the students' awareness of pragmatic features was the use of intonation and stress. As these features were part of most sentences listened to, this result is hardly surprising. Intonation and stress were introduced in the first class, and for some students it was a new area of awareness.

The second highest growth area in noticing pragmatic features was hesitators, e.g. 'um', 'ah' with a $57 \%$ increase in the number of students noticing and describing them. Hesitators were introduced early in the course and are also a very common part of interpersonal NZE discourse. Another feature showing recognition growth of $50 \%$ of students was cross-cultural awareness. 
This had high salience and high interest for the EAL (English as an Additional Language) students.

One area of cross-cultural difference was the use of silence, or lack thereof in NZE spoken discourse, while another was the level of directness in interpersonal communication. Silence has different pragmatic meanings in different cultures (Holmes, 2001). Both silence and the use of softeners showed the same rate of growth in awareness, at $42 \%$ of participants. Awareness of politeness strategies themselves did not show a high rate of growth as there was a high level of pre-awareness which was seen by the number of references to politeness in the first blog, the baseline for measuring change.

Five students referred to in-group language in their later blogs. Although in-group language was of high interest to the students, its use is limited to certain contexts which were not frequent in the conversations used for the blog analysis.

\section{Reflection}

This study affirmed the usefulness of developing suitable and valid naturalistic classroom samples. Previously there had been no resources of spontaneous NZE discourse appropriate for classroom instruction. These materials gave the impetus for finely-focused classroom content, allowing the teacher to demonstrate the use of pragmatic principles.

This study also showed that this teaching approach was effective and reinforced the teacherpractitioner's perception of the value of explicit pragmatic teaching. Even those students who reported feeling bicultural commented on the value of becoming consciously aware of the need to examine the purpose of an utterance, and not just its lexical message. Classroom discussion often led to insights, as students disagreed about the pragmatic content. Since a number of students had grown up in New Zealand they were usually able to settle any disagreements. The teacher-practitioner could stay in the background and observe the class dynamic.

The naturalness of the recordings was vital to the development of learners' ability to understand authentic dialogue. Some EAL students who had lived in New Zealand for fewer than two years said they could not hear some of the unstressed grammar words whereas native speakers hear them because they expect them to be in the sentence. After using the spontaneous examples, studio recordings in which each word was very easy to hear sounded noticeably artificial.

The classroom study based on these samples also led to a better understanding of New Zealand culture, and a more explicit understanding of some New Zealand attitudes. For example the teacher-practitioner needed to explain that New Zealanders tend to view NZ as an egalitarian society at least ideationally, and many pragmatic features are used to highlight and express these values in interactions with colleagues and peers. The manager in the previously quoted sample used a very polite indirect request form to a junior colleague, to imply equal status: if you could give me. 
The use of the students' personal blogs proved an effective learning tool, necessitating focused listening for pragmatic features outside the classroom. The blogs also provided excellent data for the study.

The findings of this study are not generalisable since the number of participants is small. This was insider research, but the coding was moderated. There may have been some 'please the teacher' elements in some of the blog comments. Nonetheless it is not possible to describe a feature without recognizing it, so we contend that the data and conclusions on awareness are trustworthy.

Future research could focus on which cross-cultural pragmatic differences learners notice. It could also explore the effectiveness of using semi-authentic texts for the teaching of pragmatics at lower levels.

Finally, the value of pragmatic study in the language classroom was demonstrated. All the students commented to some degree in the final survey on their increased ability to understand other speakers' intentions, more particularly if there was a cross-cultural component in the discourse situation. "I am much more aware of how what I say and how I say it has an influence on people I speak to. I am also more aware of sociopragmatic conventions in New Zealand" (Russian speaker).

\section{References}

Bardovi-Harlig, K., \& Dörnyei, Z. (1998). Do language learners recognise pragmatic violations? Pragmatic versus grammatical awareness in instructed L2 learning. TESOL Quarterly, 32, 233- 262.

Basturkmen, H. (2002). Learner observation of, and reflection on, spoken discourse: An approach for teaching academic speaking. TESOL Journal, 11(2), 26-30.

Burns, A. (2000). Facilitating collaborative action research: some insights from the AMEP. Prospect, 15(3), 23-34.

Denny, H. (2008). Teaching the pragmatics of negotiation in New Zealand English to adult migrants: The role of whole naturalistic texts. Prospect, 23(1), 46-57.

Denny, H., \& Basturkmen, H. (2009). Using authentic spoken texts in socio-pragmatic focused instruction: A survey of teacher practices and perspectives. Final project report. Retrieved 23 October, 2009, from http://akoaotearoa.ac.nz/ako-hub/ako-aotearoanorthern-hub/resources/pages/using-authentic-spoken-texts-socio-pragmatic-focus

Eslami-Rasekh, Z. (2005). Raising the pragmatic awareness of language learners. ELT Journal, 59, 199-208. doi:10.1093/elt/cci039

Farrell, T. S. C. (2008). Reflective practice in the professional development of teachers of adult English learners.

Gilmore, A. (2004). A comparison of textbooks and authentic interactions. ELT Journal, 58, 363374. doi:10.1093/elt/58.4.363 
Golato, A. (2003). Studying compliment responses: A comparison of DCTs and recordings of naturally occurring talk. Applied Linguistics, 24, 90-121. doi:10.1093/applin/24.1.90

Holmes, J. (2001). A introduction to sociolinguistics (2nd ed). Harlow: Longman.

House, J. (1996). Developing pragmatic fluency in English as a foreign language. Studies in Second Language Acquisition, 18, 225-252.

Kasper, G., \& Roever, C. (2004). Pragmatics in second language learning. In E. Hinkel (Ed.), Handbook of research in second language teaching and learning (pp. 317-334). Mahwah, NJ: Lawrence Erlbaum Associates.

Louie, B., Drevdahl, D., Purdy, J., \& Stackman, R. (2003). Advancing the scholarship of teaching through collaborative self-study. Journal of Higher Education, 74, 150-171.

Riddiford, N. (2007). Making requests appropriately in a second language: Does instruction help to develop pragmatic proficiency? TESOLANZ Journal, 15, 88-102.

Rose, K. (2005). On the effects of instruction in second language pragmatics. System, 33, 385399.

Schmidt, R. (1990). The role of consciousness in second language learning. Applied Linguistics, 11, 129-158. doi:10.1093/applin/11.2.129

Yates, L. (2004). The secret rules of language. Prospect, 19(1), 3-21. 


\section{Appendix 1: Blog Task Instructions}

\section{ODI Blogs first submission}

During the first 8 weeks of the semester you will keep a fortnightly journal of your growing awareness and understanding of the pragmatic content of English conversations based on the conversations we study in class, and those that you participate in or listen to. You will also comment on the differences between the pragmatic content of equivalent situations in your Language Other Than English (LOTE). Your weekly entry will be approximately 400 words, and include examples that you have analysed pragmatically. This Journal will be submitted in week 9 .

To assist you with your journal writing for the first three entries, think of a conversation you recently heard or took part in and then try to answer the following questions:

1. Who were the participants in the conversation? (friends or strangers or classmates)

2. Where was the conversation taking place?

3. What did the participants want from each other? (friendship/ help/a good time/ sympathy/ other)

4. How was the pragmatic meaning shown? (body language/ sarcasm/ exaggeration/ softeners/ hedging/ understatement/ sentence stress \& intonation/ other)

5. Would the equivalent words when interpreted into your LOTE carry the same pragmatic meaning? What does this mean to you as an interpreter?

Final journal entry, please answer these questions:

1. Did the pragmatic features we study in class help your understanding of spoken interaction?

2. How useful were the classroom examples and learning materials?

3. Do you feel you understand more about pragmatics than at the beginning of semester? Please comment.

4. Has learning about pragmatics been useful for you as a participant in English conversations, and as an interpreter? 
Appendix 2 . Changes in student awareness

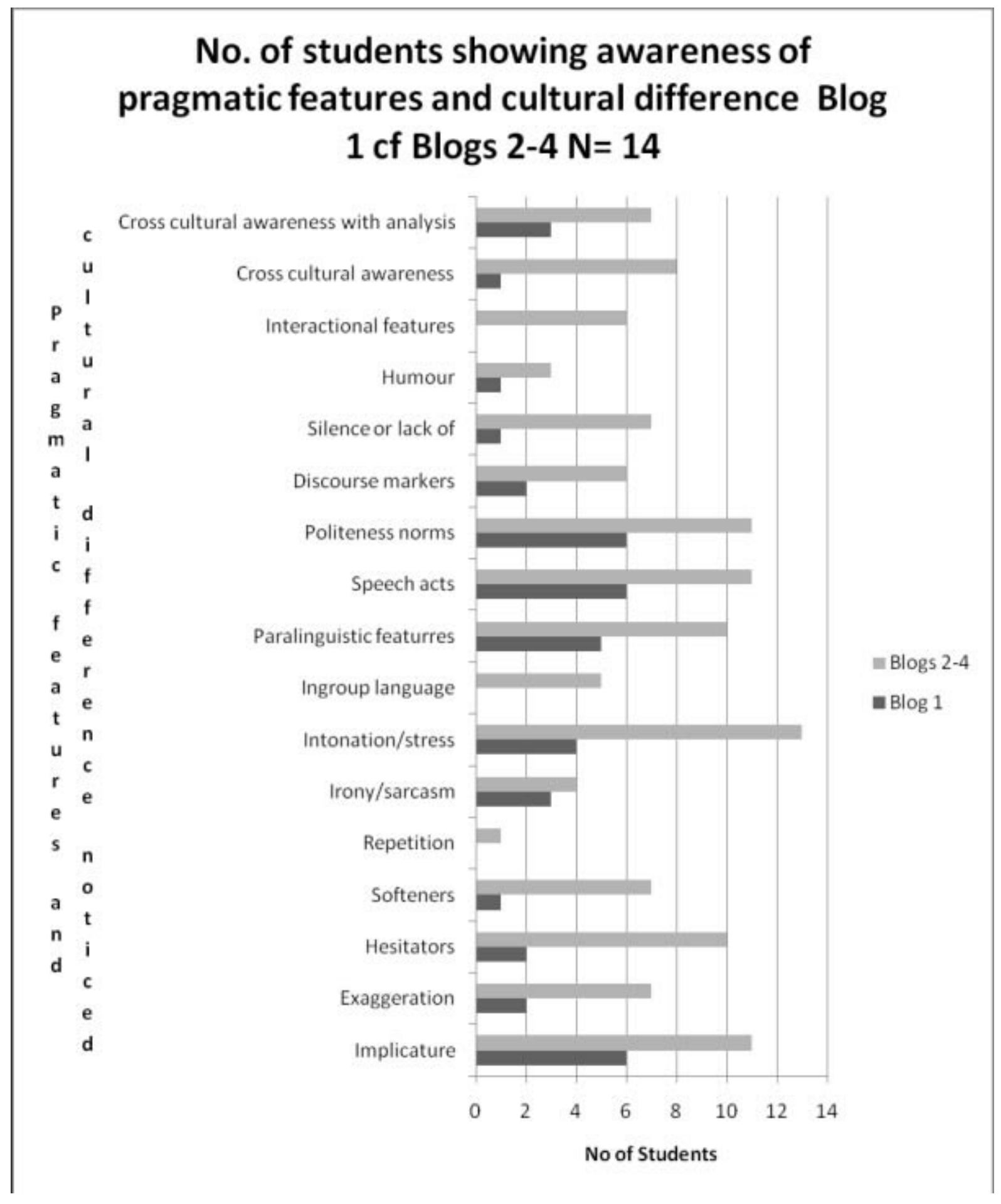

Making the implicit explicit 9 
Making the implicit explicit 10 